University of Nebraska - Lincoln

DigitalCommons@University of Nebraska - Lincoln

Transactions of the Nebraska Academy of

Sciences and Affiliated Societies

Nebraska Academy of Sciences

Spring 3-9-2020

\title{
Sandhill Crane abundance in Nebraska during spring migration: making sense of multiple data points
}

Andrew J. Caven

Platte River Whooping Crane Maintenance Trust, acaven@cranetrust.org

Dana M. Varner

Nebraska Rainwater Basin Joint Venture, dana_varner@fws.gov

Jeff Drahota

United States Fish and Wildlife Service, Jeff_Drahota@fws.gov

Follow this and additional works at: https://digitalcommons.unl.edu/tnas

Part of the Population Biology Commons

Caven, Andrew J.; Varner, Dana M.; and Drahota, Jeff, "Sandhill Crane abundance in Nebraska during spring migration: making sense of multiple data points" (2020). Transactions of the Nebraska Academy of Sciences and Affiliated Societies. 523.

https://digitalcommons.unl.edu/tnas/523

This Article is brought to you for free and open access by the Nebraska Academy of Sciences at DigitalCommons@University of Nebraska - Lincoln. It has been accepted for inclusion in Transactions of the Nebraska Academy of Sciences and Affiliated Societies by an authorized administrator of DigitalCommons@University of Nebraska - Lincoln. 


\title{
Sandhill Crane abundance in Nebraska during spring migration: making sense of multiple data points
}

\author{
Andrew J. Caven, ${ }^{1}$ Dana M. Varner, ${ }^{2}$ and Jeff Drahota ${ }^{3}$ \\ 1 Platte River Whooping Crane Maintenance Trust, Wood River, Nebraska, 68883, USA \\ 2 Rainwater Basin Joint Venture, Grand Island, Nebraska, 68803, USA \\ 3 U.S. Fish and Wildlife Service, Rainwater Basin Wetland Management District, Funk, Nebraska, 68940, USA \\ Corresponding author - acaven@cranetrust.org; (605)-252-8007
}

\begin{abstract}
The USFWS conducts an annual one-day aerial survey of the North and Central Platte River Valleys, generally on the fourth Tuesday in March, to estimate the abundance of the midcontinent Sandhill Crane population. However, these abundance indices demonstrate unrealistic inter-annual variation as a result of deviations in migration chronology and other factors. Additional research efforts have been undertaken within the region to estimate Sandhill Crane abundance over time and space but these projects generally seek to answer unique questions, employ differing survey methods, and cover overlapping yet distinct survey areas. Despite the wealth of information there remains significant uncertainty regarding the actual abundance of Sandhill Cranes in Nebraska during the peak of migration. We conducted a model-based metadata analysis relying on the distinctive strengths of three databases to assess USFWS data, identify annual abundance estimates that may not be robust, and developed parameter-based and factorbased corrections to USFWS indices from 2000 to 2019. Our analyses suggest that at the peak of spring migration there is likely between 1.1 and 1.4 million Sandhill Cranes in the North and Central Platte River Valleys of Nebraska. Our best performing models indicated the most likely peak estimate was 1.27 million Sandhill Cranes with approximately 220,000 in the North Platte River Valley and 1,050,000 in the Central Platte River Valley in both 2018 and 2019. Our assessment suggests that 25\% of USFWS aerial estimates are robust, with the rest representing underestimates as both exogenous and endogenous factors such as migration chronology and survey methodology serve to bias indices downward. Given this downward bias, the three-year running average used by the USFWS actually provides a robust estimate for only $5-15 \%$ of the years analyzed. By contrast, we found that a five-year rolling maximum provides a robust estimate for $70-75 \%$ of the years analyzed.
\end{abstract}

Keywords: midcontinent Sandhill Crane population, meta-analysis, abundance indices, North Platte River Valley, Central Platte River Valley

DOI: $10.32873 /$ unl.dc.tnas.40.2

\section{Introduction}

The midcontinent Sandhill Crane (Grus canadensis) population (MCP) has a wintering distribution from coastal Texas west to southeastern Arizona and a breeding distribution from Hudson Bay, Canada, west to Siberia, Russia. However, the migratory pathway funnels through a relatively narrow band centered along the North Platte and main-stem Platte Rivers in Nebraska each spring (Tacha et al. 1984, Krapu et al. 2011). Estimates are that the vast majority of the MCP stages in Nebraska during the spring migration with approximately $15-20 \%$ staging somewhere in the North Platte River Valley (NPRV) and 80-85\% staging in the Central Platte River Valley (CPRV; Krapu et al. 2011, Silcock and Jorgenson 2019). Individual cranes tend to stage in Nebraska a little over 3 weeks, with variation in stay length and chronology by regional breeding affiliation (Krapu et al. 2014). The first individuals tend to ar- rive in mid-late February and the last generally depart within the first two weeks of April (Krapu et al. 2014, Silcock and Jorgenson 2019). However, recent research indicates that the Sandhill Crane migration has been advancing earlier into the spring over the last few decades and that the timing of migration staging in Nebraska has broadly become more variable (Caven et al. 2019). Recent research has also documented occasional wintering in Nebraska in recent years (Harner et al. 2015).

Sandhill Crane spring staging in Nebraska presents a rare opportunity for wildlife researchers to estimate the abundance of a wide-ranging species by intensively surveying a relatively small area (Benning and Johnson. 1987, Kinzel et al. 2006, Caven et al. 2019). Beginning in 1957 , annual aerial surveys were conducted by flying north-south transects spaced 1 mile apart and counting all cranes within a half-mile $(800 \mathrm{~m})$ of the aircraft in areas of high crane density, while surveying in a zig-zag 
pattern across areas of lower density (Wheeler and Lewis 1972). Beginning in 1972 the USFWS changed techniques to surveying roosts, adjacent meadows, and fields within 1 mile $(1.6 \mathrm{~km})$ of the main channel of the Platte River beginning at daybreak and continuing for 1 hour (hr.), taking two to three mornings to cover the entire survey area (Lewis 1978). These methods were abandoned because estimates were highly impacted by the number of birds remaining on the river as the survey plane passed (Lewis 1978, Ferguson et al. 1979). This method was replaced with an updated daytime north-south transect survey protocol in 1979, which itself was improved upon by the addition of photo-based bias correction procedures in 1982 that continue to be used today (Ferguson et al 1979, Benning and Johnson 1987, Figure 1). The USFWS aerial survey is paired with additional surveys conducted at key sites within the migration path (TX, OK, KS, NE, SD, $\mathrm{ND}, \mathrm{WY}$ ) to constitute the coordinated spring survey of MCP (Dubovsky 2018, Liddick 2019). However, these additional survey efforts do not include bias correction procedures and are generally conducted from the ground (Dubovsky 2018, Liddick 2019).

Pending appropriate weather the USFWS aerial survey is conducted on the fourth Tuesday of March (Benning and Johnson 1987, Dubovsky 2018). However, Pearse et al. (2015) determined that the USFWS abundance estimates demonstrated biologically infeasible inter-annual variation (i.e. - unrealistic changes considering Sandhill Crane population ecology) as a result of deviations in the proportion of the MCP present in the CPRV and NPRV during the official survey. Pearse et al. (2015) found that between $71 \%$ and $94 \%$ of Sandhill Cranes marked with very-high-frequency transmitters were within the Platte River Valley on the USFWS specified aerial survey date between 2001 and 2006 as a result of temporal variation in peak migration. Relatedly, Caven et al. (2019) detected variations in the date of Sandhill Crane peak abundance in the CPRV ranging from 8 March to 8 April from 2002 to 2017. Seasonal weather patterns can have a significant impact on migration chronology. Caven et al. (2019) found that increased mean temperature and the Palmer Drought Severity Index measures at major Sandhill Crane wintering sites were associated with advanced arrival dates of significant percentiles of the MCP to the CPRV. Furthermore, Krapu et al. (2014) found that Greater Sandhill Crane departure dates were negatively correlated with temperatures in late March and early April. Therefore, survey protocols that attempt to assess the abundance of the Sandhill Crane population at only a single point in time are highly influenced by the percentage of the population present in the NPRV and CPRV, which itself is subject to climatic influences. Ferguson et al. (1979) noted this problem during the development of the current USFWS aerial survey protocol and recommended conducting three to four weekly surveys to improve abundance estimates.

Along with long-term annual USFWS aerial surveys, additional projects have been completed by various organizations to further clarify details of Sandhill Crane migration chronology, relative roosting densities, habitat selection, and to develop new methods for assessing abundance (Sidle et al. 1993, Davis 2003, Kinzel et al. 2006, Baasch et al. 2019, Varner et al. 2019, Caven et al. 2019). Theoretically, these additional survey programs supplement our understanding of USFWS abundance indices and provide a more complete picture of the MCP. Practically, a major complication has been that the various survey programs have different objectives, survey areas, and operational time periods, which has resulted in a general sense of uncertainty regarding MCP abundance estimates.

Sandhill Crane survey programs are subject to a number of exogenous factors including migration chronology as well as endogenous factors such as survey methodology that impact abundance estimates. For instance, Norling et al. (1992) noted that early in the spring migration $74 \%$ of Sandhill Cranes left the roost before sunrise, yet only about $17 \%$ left before sunrise later in March and into April. Lewis $(1974,1979)$ suggested that about $18 \%$ of Sandhill Cranes left their roosts before sunrise in Oklahoma and 25\% left the Platte River before sunrise from mid-March to early April. Additionally, Norling et al. (1992) demonstrated that daily weather conditions impacted riverine roost departure and arrival times. Relatedly, Sparling and Krapu (1994) noted that flight distances to diurnal foraging sites increased from early in migration to its peak. Therefore, survey programs focused on the estimating abundance using early morning flights following riverine roosting locations can be significantly impacted by daily crane movements (Lewis 1979, Ferguson et al. 1979).

To better estimate the number of Sandhill Cranes that stage in Nebraska during the spring migration we have conducted a model-based metadata analysis relying on three databases with distinct strengths and weaknesses to develop corrections to USFWS data (Kinzel et al. 2006, Stewart 2009, Caven et al. 2019, Varner et al. 2019). In particular, our aim is to identify survey years when estimates may not be robust and to correct those indices with 


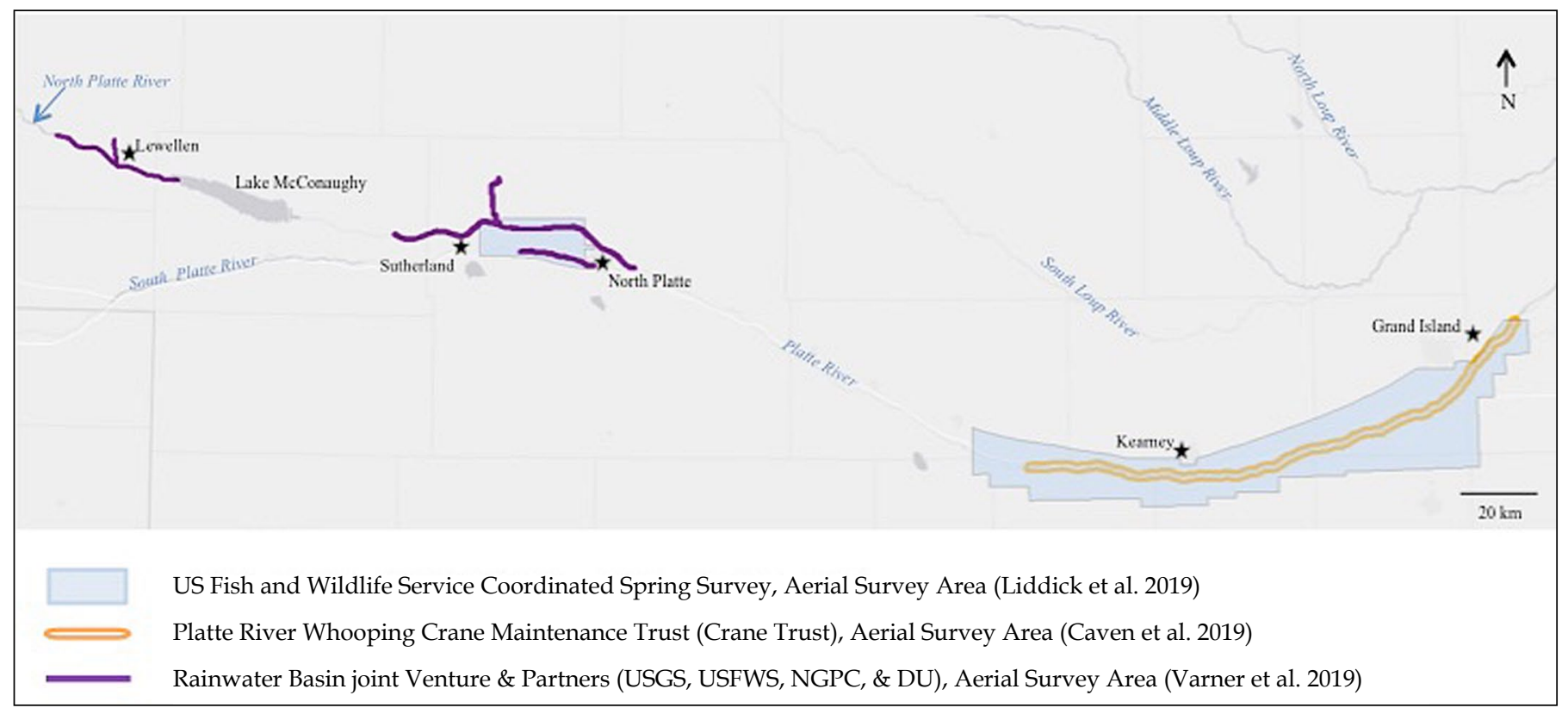

Figure 1. Study area map of the North, South, and Central Platte River Valleys including the USFWS aerial survey areas (blue polygon), the Crane Trust aerial survey area (orange polygon), and the Rainwater Basin Joint Venture aerial survey areas (purple polygon).

model-based parameter estimates (White 2005, Stewart 2009). We also estimated population growth rates from 2000 to 2019 using USFWS data as well as the models we developed to investigate the models' biological feasibility.

\section{Study Sites}

The NPRV and CPRV are historically prairie braidedriver systems that provide secure open roosting habitat to Whooping Cranes and Sandhill Cranes (Smith 1971, Krapu et al. 1982, Farmer et al. 2005). However, the ecosystem has been altered over the last century by human activities and has transitioned to a more meandering, anabraching, and wooded river in many reaches (Williams 1978, Currier 1982, Horn et al. 2012). Sandhill Crane use was likely contiguous throughout the NPRV and CPRV, but Sandhill Cranes largely abandoned the reach below Kingsley Dam to Sutherland as well as from North Platte to Overton, Nebraska, following widespread damming and diversion of the Platte River (Walkinshaw 1956, USFWS 1981, Krapu et al. 1982, Figure 1). Sandhill Crane abandonment was associated with declines in appropriate roosting habitat as channel width decreased by up to $90 \%$ in some reaches from 1865 to 1969 and large portions of the former channel were replaced by riparian woodland (Walkinshaw 1956, Williams 1978, USFWS 1981, Krapu et al. 1982). More recent research indicates that shifts in the densities of Sandhill Cranes from central and western to eastern portions of the CPRV are continuing (Faanes and LeValley 1993, Buckley 2011, Caven et al. 2019). Sandhill Crane spring staging was likely historically tied to predictably abundant resources provided by large expanses of wetlands and the secure wide channels for roosting that once existed throughout the North and Central Platte River Valleys (Krapu 1999, Warnock 2010). Today much of this land has been converted to row crop agriculture and the expanse of wetlands have been reduced as a result of human appropriation of Platte River flows and drainage (Sidle et al. 1989). However, Sandhill Cranes have adapted relatively well to agriculture, particularly corn cultivation, and continue to stage in parts of the NPRV and CPRV in large numbers (Pearse et al. 2010, Krapu et al. 2014, Nowald et al. 2018).

\section{Material and Methods}

\section{Data Sources}

Kinzel et al. (2006) used aerial thermal-imagery to estimate the number of river-roosting Sandhill Cranes on three to five nights ( 2100 to $0200 \mathrm{hrs}$.) each year in late March from 2000 to 2003 between Lexington and Grand Island, Nebraska. This abundance estimate is often regarded as one of the most accurate for a particular time 
and location, recording a maximum count of 552,000 \pm 38,000 in 2000 (Kinzel et al. 2006, Krapu et al. 2014, Pearse et al. 2015). The Kinzel et al. (2006) results were higher than the USFWS photo-corrected ocular survey estimates $(490,100 \pm 71,800$ in 2000) for every year of the study despite covering a smaller survey area. This study effectively reduced variability in the number of cranes within the survey area by surveying at night, but did not account for year-to-year variation in migration chronology.

From 2002 to 2019 the Crane Trust conducted early morning aerial surveys between Chapman and Overton, Nebraska, via a method reminiscent of the daybreak surveys flown along the river by the USFWS in the 1970s (Lewis 1979, Buckley 2011, Caven et al. 2019; Figure 1). However, the Crane Trust's surveys were conducted weekly from mid-February to mid-April, allowing for a valuation of peak abundance timing, and as of 2016 included a photo-based bias-correction procedure (Caven et al. 2019). Estimates produced via this method peaked in 2019 at $659,870 \pm 61,378$, and are generally lower than USFWS aerial estimates $(945,996 \pm 133,127$ in 2019) but are also conducted over a smaller area. The Crane Trust survey area predominantly overlaps the Kinzel et al. (2006) study area with the omission of a western segment from Overton to Lexington, but it also includes a portion east of highway 34 to Chapman, not surveyed by Kinzel et al. (2006). In contrast to Kinzel et al. (2006), this long-term study does a relatively good job of accounting for migration chronology, but does not control for day-to-day variability in the number of cranes outside of the survey area.

Crane Trust surveys did not set a detection limit, but included all cranes that could be positively identified with binoculars from the flight path (Caven et al. 2019). In 2018 Crane Trust staff recorded detection distances for a random subset of Sandhill Crane groups recorded in off-channel habitats such as wet meadows and cornfields along the survey path, which suggested that groups within $3.4 \mathrm{~km}(2.1 \mathrm{mi})$ of the south channel of the Platte River were regularly detected $(\bar{x}=2.2 \mathrm{~km}, \mathrm{sd}=1.2 \mathrm{~km}, \mathrm{n}$ $=16$ ). However, their detectability was likely reduced in comparison to those cranes remaining on the river. It is unclear what percent of cranes departing the river early typically moved beyond Crane Trust survey detection limits. Comparatively, the USFWS survey area exceeds 10 $\mathrm{km}$ distance from the river in certain locations and Pearse et al. (2015) found that between 0 and $11 \%$ of the Sandhill Cranes in the CPRV were outside of this area during surveys between 2001 and 2007 (Figure 1).
Varner et al. (2019) employed a similar daybreak aerial survey method to Lewis (1979) and Caven et al. (2019) to assess relative abundance in areas of the NPRV from North Platte to Sarben including the tributary of Birdwood Creek, and from Lake McConaughy to Oshkosh, Nebraska, as well as the South Platte River Valley (SPRV) from North Platte to Hershey, Nebraska (Figure 1). Varner et al. (2019) flew surveys at a lower altitude than either Lewis (1979) or Caven et al. (2019) and therefore had narrower detection limits (800 $\mathrm{m}$ total coverage). Varner et al. (2019) conducted aerial surveys weekly from late February to early April but did not include a bias-estimation procedure. Previous data suggests that aerial counts of Sandhill Cranes that are not bias-corrected using photographic techniques or other processes generally represent underestimates (Ferguson et al. 1979, Benning and Johnson 1987, Gregory et al. 2004). The major strengths of this survey program are that it accounts for migration chronology and includes significant coverage outside of the official USFWS aerial survey area. However, the narrow survey area and lack of error correction likely biases estimates downward.

\section{Statistical Analyses}

Given the probability that abundance indices derived from Varner et al. (2019) represent underestimates, we combine the maximum count from those surveys $(90,000)$ with Crane Trust photo-corrected peak estimates from 2016 to 2019 to determine an estimate for the CPRV and NPRVs via first light aerial roost surveys. Secondly, we added $15 \%$ to the Kinzel et al. (2006) abundance estimates from 2000 to 2003 to account for the NPRV, which was not surveyed (Krapu et al. 2011). We then compared the results from these adjusted estimates to USFWS data to improve interpretation of the various databases and to derive corrective adjustments if possible. Then, we developed a merged database comprised of information derived from all four databases including the USFWS, Crane Trust (Caven et al. 2019), Varner et al. (2019), and Kinzel et al. (2006). We developed covariates to predict USFWS aerial abundance estimates from data associated with each database as well as the databases' relationships to each other. Covariates included the number of days between the Crane Trust survey indicating peak abundance and the USFWS aerial survey, the percent of Sandhill Cranes counted during the USFWS aerial survey of the NPRV and CPRV as compared to at other locations during the coordinated mid-continent survey, the calen- 
dar year the survey was conducted, and the percentage of peak abundance detected during the Crane Trust survey nearest in date to the USFWS survey.

We ran ordinary least squares multiple linear regression models with and without a log-transformed outcome variable and compared models using AICc to determine top model covariates predicting USFWS aerial abundance indices using the "stats" and the "MuMIn" packages in R 3.2.1 (Burnham et al. 2011, R Core Team 2015, Barton 2016). No independent variables with a correlation higher than $r=|0.50|$ were included within the same model (Dorman et al. 2013). Competing models were determined a priori considering the various sources of bias influencing USFWS aerial estimates (chronological, methodological, etc.). We then applied parameter estimates from top model covariates to USFWS aerial survey data to create corrected estimates. Despite the fact log-transformed models outperformed corresponding untransformed ones, equations from basic linear regression equations were also used in some corrective abundance models because exponential (log-transformed) parameter estimates were potentially biased downward during low count years as they were operationalized as a proportion of that year's abundance. We capped corrections based on the percent of Sandhill Cranes counted during the USFWS aerial survey portion of the coordinated midcontinent survey at $97 \%$ because this represented the maximum value in the data between 2000 and 2019. We also made competing adjustments to USFWS estimates using correction factors developed from comparisons between Kinzel et al. (2006) and USFWS data (Liddick 2019). These "Kinzel-correction factors" accounted for protocolderived bias in USFWS data as these surveys were conducted within the same time period (Kinzel et al. 2006). By contrast, model based corrections derived from Crane Trust data focused on correcting chronology-based biases in USFWS data (Caven et al. 2019). Based on data comparisons, Kinzel-correction factors included dividing USFWS estimates by 0.80 if they were within one confidence interval of the five-year USFWS rolling maximum, dividing by 0.72 if more than one confidence interval below the fiveyear USFWS rolling maximum, dividing by 0.63 if more than two confidence intervals below, and by 0.55 if more than three confidence intervals below (all confidence intervals were separated by $\sim 0.083$ ). Finally, we created hybrid models using covariate-based adjustments including both linear (true number) and exponential (percentage) equations in conjunction with Kinzel-correction factors. We also developed competing abundance estimates us- ing basic calculations with USFWS data, including the five-year rolling maximum, the three-year rolling maximum, and the three-year rolling average (currently in official use - Dubovsky 2018).

We evaluated these models in two ways. First, we created projections using Kinzel et al. (2006) and USFWS estimates (Liddick 2019) from the year 2000 as starting points and estimated growth curves from ordinary least squares multiple regression models of log-transformed USFWS abundance indices by survey year from 2000 to 2019. We estimated confidence intervals surrounding these projections using mean $( \pm 12 \%)$ and maximum $( \pm 16 \%)$ confidence internal values reported by the USFWS (Liddick $2019)$ and maximum confidence interval values $( \pm 7 \%)$ reported by Kinzel et al. (2006). We then calculated the percentage of values derived from various abundance models that fell within the "cone of confidence" surrounding various projections (See Nelson et al. 2010). Secondly, we evaluated all abundance estimates by fit to survey year using AICc, assuming that models that were better predicted by survey year likely displayed less random variation and were therefore more robust.

\section{Results}

Estimates of abundance in the CPRV and NPRV based on Kinzel et al. (2006) data were $22.8 \%$ to $43.6 \%$ higher than USFWS aerial estimates from 2000 to 2003 ( $\bar{x}=33.5 \pm 10.5$; Figure 2). USFWS estimates were $31.6 \%$ higher to $25.4 \%$ lower than Crane Trust estimates $(\bar{x}=8.9 \pm 24.7$, including Varner et al. 2019; Figure 3). In 2018, when the surveys were conducted on the same day, the USFWS estimate was $31.6 \%$ higher than the Crane Trust's. However, in 2016, when the USFWS survey was conducted 8 days after Crane Trust detected peak abundance the USFWS estimated was $25.4 \%$ lower.

The top model predicting log-transformed USFWS photo-corrected annual abundance was the number of days between the USFWS aerial estimate and when the Crane Trust detected peak abundance ("DFP", $B=-0.011$ ), the percentage of Sandhill Cranes counted within the USFWS aerial survey area during the coordinated midcontinent survey effort (“\% NE", $B=0.044$ ), and survey year ("Year", $B=0.035$; Table 1). Corresponding linear parameter estimates for the top model were $B=-7,841$ (DFP), $B$ $=17,907(\% \mathrm{NE})$, and $B=21,125$ (Year), respectively (see "Notes" Table 1). However, another model within AICc delta 2 also included the percentage of the annual peak Crane Trust estimate counted during the survey nearest 


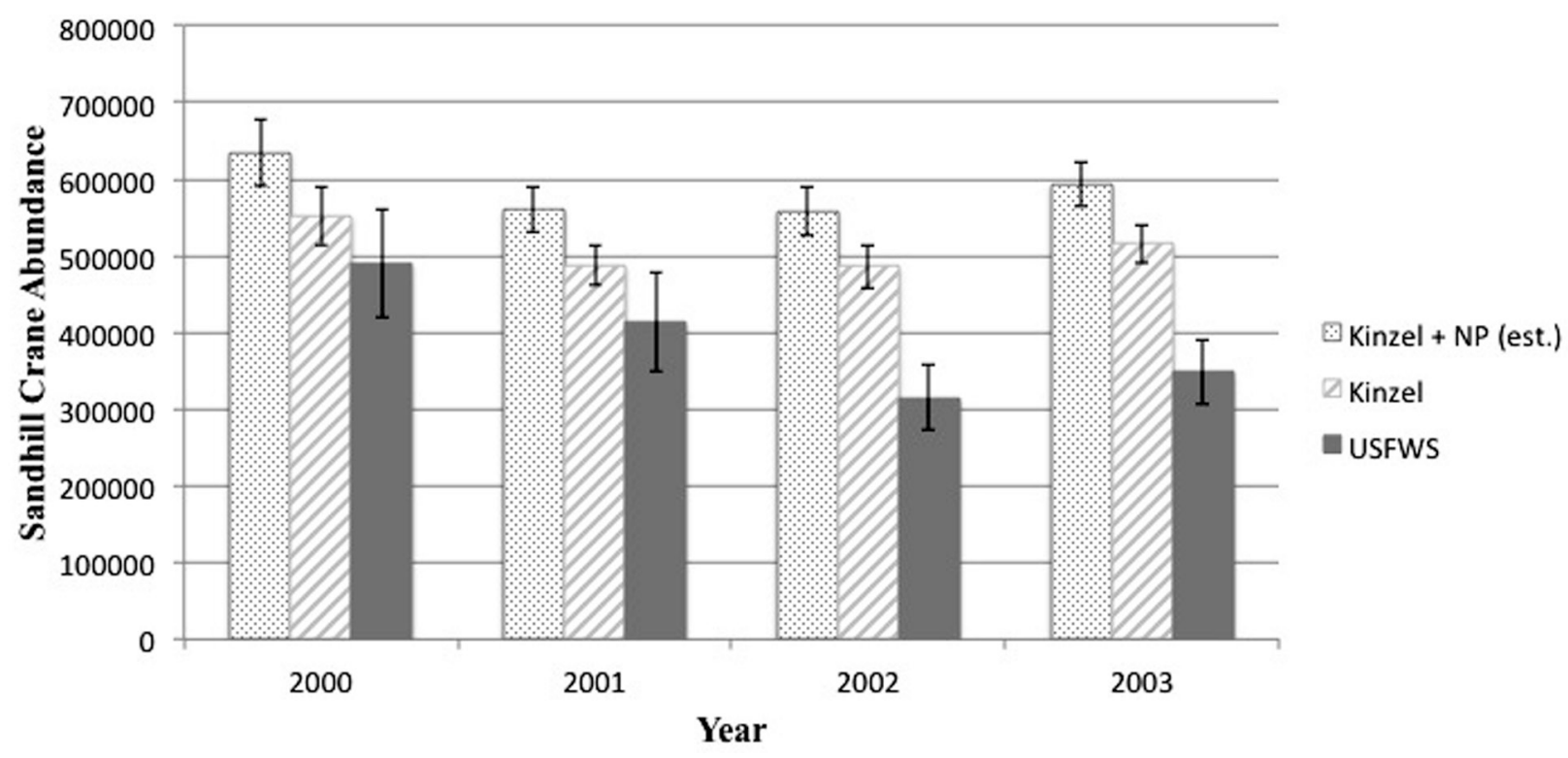

Figure 2. Sandhill Crane abundance from USFWS aerial surveys, Kinzel et al. (2006) aerial thermal-imagery, and an estimate of Kinzel et al. (2006) including the NPRV from 2000 to 2003.

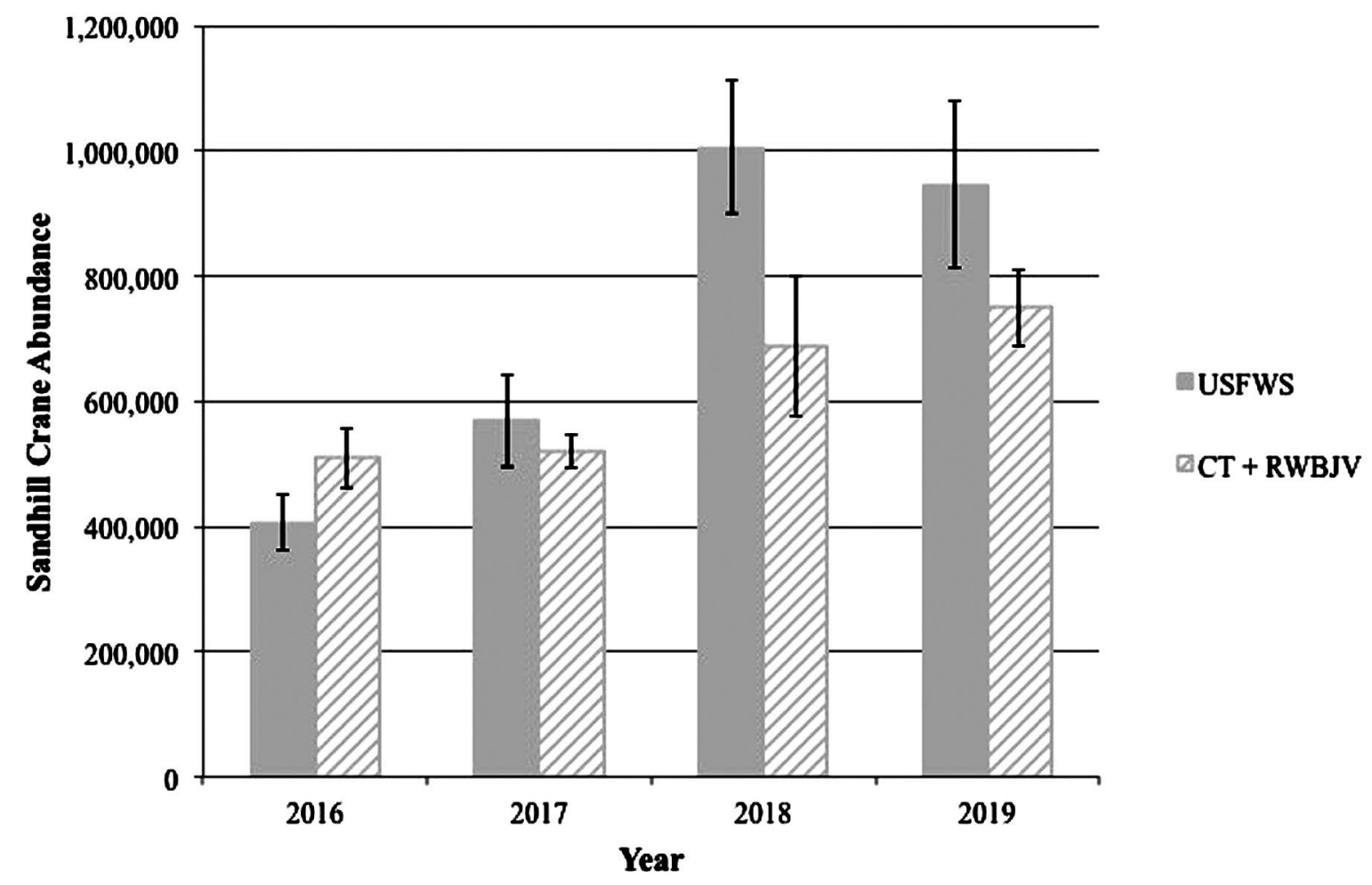

Figure 3. Sandhill Crane abundance from USFWS aerial surveys (NPRV + CPRV) and Crane Trust aerial surveys (CPRV) including maximum count data from Rainwater Basin Joint Venture coordinated surveys of the NPRV (Varner et al. 2019) from 2016 to 2019.

in date to the USFWS survey $(B=0.084$; Table 1$)$. All statistical models outperformed corresponding null models $(\log (\mathrm{DV}) \sim 1$ or DV $\sim 1$; Table 1$)$.
Peak abundance estimates from corrective models for 2018 and 2019 ranged from 1,031,100 (multivariate linear covariate correction) to $1,390,600$ (hybrid model with ex- 
Table 1. Model selection table of covariates predicting Sandhill Crane abundance as measured by USFWS aerial surveys from 2000 to 2019.

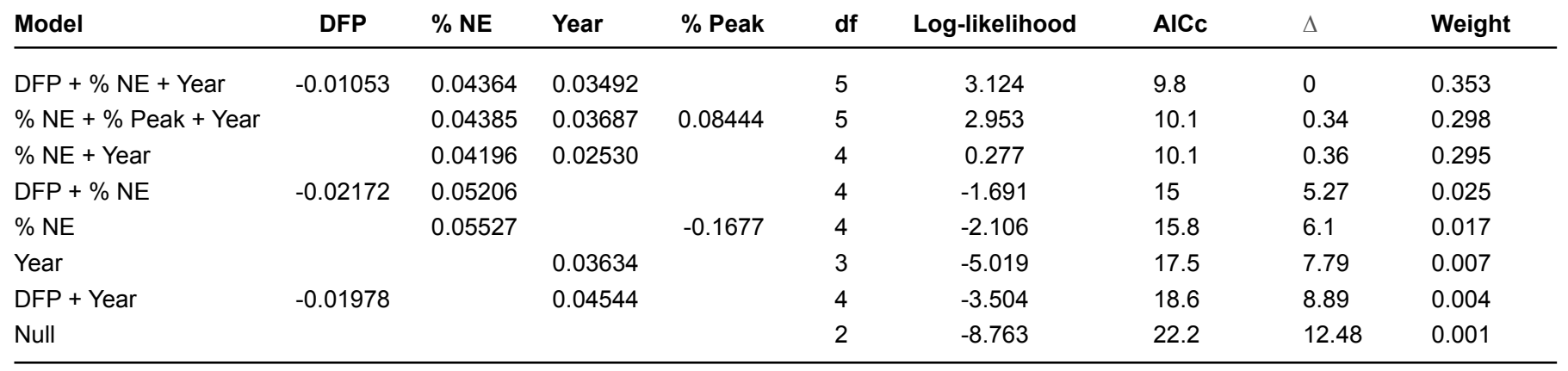

Notes: "DFP" = Number of days from CT peak survey date USFWS aerial survey was conducted; "\% NE" = Percentage of Sandhill Cranes counted within the USFWS aerial survey area as opposed to outside it during the coordinated midcontinent survey; "Year" = calendar year survey was conducted; "\% Peak" = Percentage of the annual peak CT survey counted during the CT survey nearest in date to the USFWS. Models with log-transformed outcome variables outperformed like linear models, and therefore linear models were not presented in this table.

ponential covariates; Table 2). Of the five corrective models, three suggested peak abundance in 2019 and two in 2018 (Table 2). The USFWS aerial survey data had a peak abundance of 1,005,600 in 2018, which is significantly higher than the three-year average of aerial survey data $(840,000)$ (Table 2). We determined a $3.7 \%$ growth rate in the MCP from the USFWS aerial survey data. Using the USFWS aerial estimate from 2000 as a starting point we projected the 2019 point estimate of abundance at 977,500 , or from 860,200 to $1,094,800$ applying a $12 \%$ confidence interval or from 821,100 to $1,133,800$ using a $16 \%$ confidence interval (Figure 4). Using the Kinzel et al. (2006) estimate for 2000 as a starting point we projected an abundance of $1,266,000$ for 2019 , or a range from $1,177,400$ to $1,354,600$ applying a confidence interval of $7 \%$ (Figure 4 ).

The model that performed best by the cone of confidence assessment method for the projection based on USFWS aerial survey data was the USFWS five-year rolling maximum, which fell within the $12 \%$ confidence in- terval projections $70 \%$ of the time and within the $16 \%$ confidence interval projections $75 \%$ of the time (Figure $4,5)$. However, $0 \%$ of these values fell within the Kinzel et al. (2006)-based projection's cone of confidence. The hybrid model including both the Kinzel correction factors and model-based corrections using linear covariates performed the best regarding the projections based on Kinzel et al. (2006), falling within the 7\% confidence interval $40 \%$ of the time (Figure 5). The hybrid model utilizing exponential covariates actually overshot projections based on Kinzel et al. (2006) $45 \%$ of the time and only fell within the cone of confidence $25 \%$ of the time. Growth rates from 2000 to 2019 derived from model-based corrections as well as basic statistical manipulations of USFWS aerial survey data ranged from $2.1 \%$ (hybrid model with linear covariates) to $4.3 \%$ (five-year rolling maximum FWS; Table 3). The mean growth rate of all models, basic data transformations, and real data was 3.3\% and the median was $3.4 \%$.

Table 2. High, low, and mean abundance estimates derived from data, basic manipulations, and corrective models.

\begin{tabular}{lccc} 
Model & High - Year & Low - Year & Mean \pm SD \\
\hline Hybrid Model Exponential Covariates & $1,390,614-2019$ & $633,261-2007$ & $928,168 \pm 219,431$ \\
Hybrid Model Linear Covariates & $1,274,922-2018$ & $612,966-2007$ & $880,950 \pm 194,129$ \\
Kinzel Correction Factors & $1,257,015-2018$ & $394,200-2006$ & $746,552 \pm 230,358$ \\
Multivariate Exponential Covariate Correction & $1,112,491-2019$ & $391,947-2012$ & $645,755 \pm 203,985$ \\
Multivariate Linear Covariate Correction & $1,031,081-2019$ & $422,502-2012$ & $659,813 \pm 172,396$ \\
5-Year Rolling Maximum FWS & $1,005,612-2018$ & $490,118-2003$ & $679,418 \pm 186,562$ \\
3-Year Rolling Maximum FWS & $1,005,612-2018$ & $413,498-2003$ & $640,564 \pm 187,720$ \\
FWS Photo-Corrected Estimate Aerial Survey & $1,005,612-2018$ & $216,810-2006$ & $525,415 \pm 211,481$ \\
3-Year Rolling Average FWS & $839,992-2019$ & $358,855-2003$ & $495,464 \pm 127,102$ \\
\hline
\end{tabular}




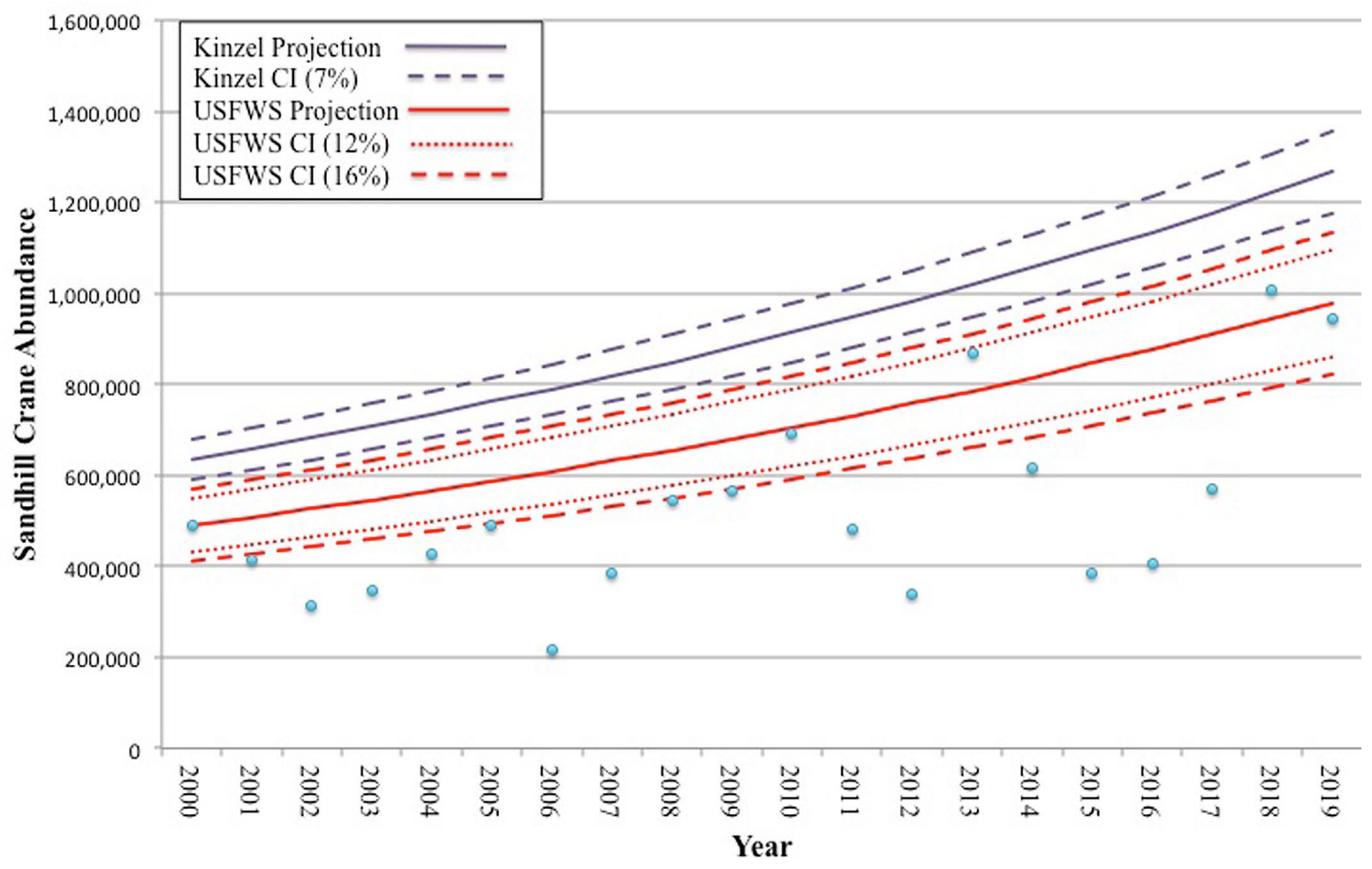

Figure 4. Projections based on an estimated $3.7 \%$ growth rate using abundance data recorded in 2000 by the USFWS and Kinzel et al. (2006) with an additional 15\% added to represent the North Platte River Valley. Projections include confidence intervals based on mean (USFWS) and maximum (USFWS, Kinzel et al. 2006) standard errors. Blue points represent actual abundance estimates from USFWS aerial surveys.

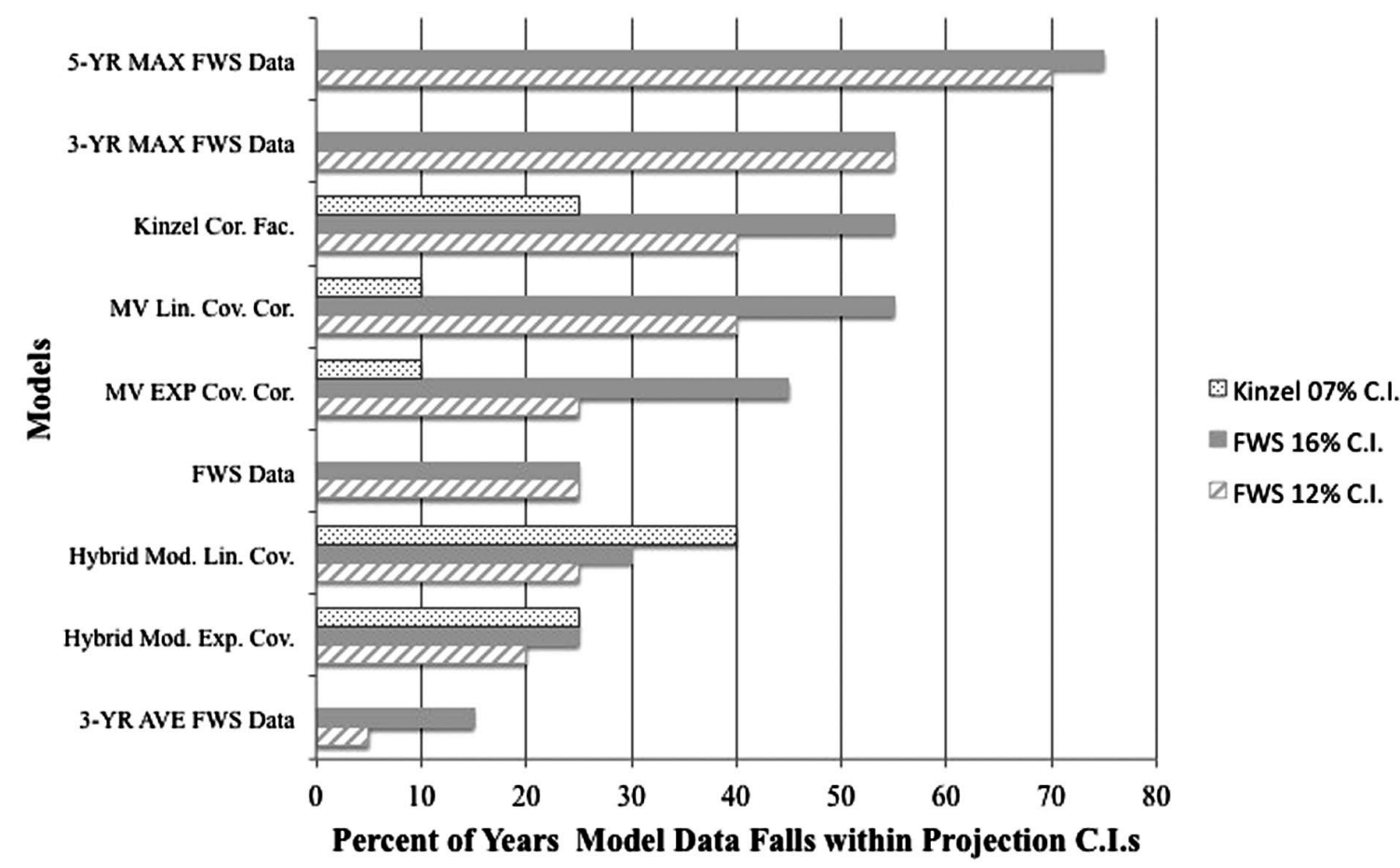

Figure 5. The percentage of years in which competing models produced values that fell within the confidence intervals surrounding USFWS $(12 \%, 16 \%)$ and Kinzel et al. $2006(7 \%)$ based abundance projections. 
Table 3. Table comparing the fit of models for predicting Sandhill Crane abundance in Nebraska by survey year.

\begin{tabular}{|c|c|c|c|c|c|c|c|}
\hline Model & Intercept & Year & df & Log-likelihood & $\mathrm{AlCc}$ & $\Delta$ & Weight \\
\hline Hybrid Model Linear Covariates & -39.28 & 0.02635 & 3 & 11.114 & -14.7 & 12.3 & 0.002 \\
\hline 3-Year Rolling Average FWS & -49.48 & 0.03114 & 3 & 9.538 & -11.6 & 15.45 & 0 \\
\hline 3-Year Rolling Maximum FWS & -64.16 & 0.03856 & 3 & 8.852 & -10.2 & 16.82 & 0 \\
\hline Kinzel Correction Factors & -63.31 & 0.03821 & 3 & 5.447 & -3.4 & 23.64 & 0 \\
\hline Multivariate Exponential Covariate Correction & -40.61 & 0.02684 & 3 & 0.039 & 7.4 & 34.45 & 0 \\
\hline FWS Photo-Corrected Estimate Aerial Survey & -59.93 & 0.03634 & 3 & -5.019 & 17.5 & 44.57 & 0 \\
\hline Null Model & 13.1 & & 2 & -8.763 & 22.2 & 49.26 & 0 \\
\hline
\end{tabular}

The model that performed best in terms of the fit to survey year was the five-year rolling maximum derived from USFWS data, followed by the hybrid model with linear covariates and the hybrid model exponential covariates, which both outperformed the rolling three-year maximum as well as the rolling three-year average derived from USFWS aerial survey data (Table 3). All models outperformed the null model (Table 3).

\section{Discussion}

Our projections and models broadly suggest that there is between 1.1 and 1.4 million Sandhill Cranes in Nebraska within the CPRV and NPRV at peak abundance during spring staging. This would roughly equate to 165,000 to 210,000 in the NPRV and 935,000 to $1,190,000$ in the CPRV based on an estimate of $15 \%$ staging in the NPRV or 220,000 to 280,000 in the NPRV and 880,000 to $1,120,000$ in the CPRV based on an estimate of $20 \%$ of the MCP staging in the NPRV (Krapu et al. 2011, Silcock and Jorgenson 2019). However, our top models broadly pointed to $\sim 1,270,000$ as the most probable point estimate of peak abundance in the CPRV and NPRV, considering the Kinzel-based projection and the models that performed best in reference to it (Tables 2, 3; Figures 4, 5). Assuming the median value of $17.5 \%$ of the MCP staging in NPRV this would equate to $\sim 222,000$ in the NPRV and $1,048,000$ in the CPRV. There may be as many as 1.5 million Sandhill Cranes in the MCP given that the vast majority stage within the CPRV and NPRV (Krapu et al. 2011) and on average $86 \%$ are present there during the peak of migration (range $=71$ to $94 \%$; Pearse et al. 2015).

The hybrid model with linear covariates performed the best regarding the Kinzel-projection as well as second best (not within AICc delta 2) via AICc (Table 3, Fig- ure 5). This estimate may be the most robust estimate at $1,274,900$ and is the nearest to the Kinzel-based projection point estimate of 1,266,000. The hybrid model with exponential covariates had the highest projected abundance at $1,390,600$, but it was not the best performing model by any evaluation metric. However, that does not totally invalidate the estimate. We tested projections based on assumptions derived from the USFWS data such as a 3.7\% population growth rate over the last 20 years. If the real annual growth rate is higher than $3.7 \%$ the hybrid model with exponential covariates may be more accurate than our evaluations indicate.

The abundance estimates presented here represent the highest valuations of the MCP in the scientific literature (Benning and Johnson 1987, Kinzel et al. 2006, Dubovsky 2018, Liddick 2019). However, in some senses these estimates may prove to be relatively conservative. The USFWS abundance indices from the early 2000s were consistently lower than those produced by Kinzel et al. (2006); yet using the same survey protocol the USFWS estimated around 1 million Sandhill Cranes in both 2018 and 2019. We know from basic comparisons that Kinzel et al. (2006) estimates (including $+15 \%$ for the NPRV) were on average just over $33.5 \%$ higher than USFWS estimates, applying simple math would suggest that a peak estimate of over 1.3 million Sandhill Cranes is very possible. The USGS and the USFWS have continued to develop thermal census techniques to repeat a similar study to Kinzel et al. (2006), which could potentially produce higher and more accurate estimates than we have presented here (personal communication, David A. Brandt, USGS).

The maximum estimate from the coordinated midcontinent survey was $1,047,100$ including all areas surveyed throughout the Great Plains, with 1,005,600 coming from official aerial surveys of the NPRV and CPRV 
(Dubovsky 2018, Liddick 2019). The number of Sandhill Cranes counted outside of the NPRV and CPRV aerial survey areas was not an accurate estimate of abundance outside of this area. However, it was a valid index and therefore covariate predicting abundance via USFWS aerial surveys (Table 1). A 1\% increase in the number of Sandhill Cranes counted outside of the USFWS aerial survey area meant a $4.5 \%$ decrease in the number counted within the area. This suggests, unsurprisingly, that Sandhill Cranes are much less detectable outside of the NPRV and CPRV survey areas (See Krapu et al. 2011 for range).

There were years when Crane Trust observations (combined with Varner et al. 2019) estimated more Sandhill Crane abundance than USFWS aerial estimates. However, this occurred only when USFWS surveys were conducted at an inappropriate time to accurately capture peak abundance. Our analyses suggests that adding about $30 \%$ to Crane Trust peak surveys would provide an estimate commensurate with the USFWS for the year if surveys are conducted within the same time window.

Competing model-based estimates may perform well in different regards (Schuwirth et al. 2019). For instance, some may do well estimating overall abundance while others do a better job estimating growth rate. Though the abundance estimates resulting from the hybrid model with linear covariates may have been the most robust by some measures, they may not have provided the best estimation of the annual growth rate. This model predicted the lowest annual growth rate at $2.1 \%$ despite producing the second highest abundance estimate. This may have been a result of abundance estimates being overcorrected early in the dataset when the population was lower while being potentially under-corrected more recently as parameter estimates used to corrected data were static across the 20-year dataset. Because the linear covariate estimates represent an average slope across the entire database it is likely that they are more reflective of the higher values observed more recently (Rousseeuw and Van Zomeren 1990). This equation therefore may have underestimated the population growth rate while providing a relatively accurate abundance estimate. The USFWS five-year rolling maximum, which performed very well in all tests except in regard to Kinzel-based projections, actually estimated a $4.3 \%$ growth rate. The mean growth rate of all models, basic data transformations, and real data was 3.3\% and the median was $3.4 \%$. However, as the five-year rolling maximum was the best model as predicted by survey year it is possible that those values on the upper end of annual growth rate estimates from $3.7 \%$ to $4.3 \%$ are most valid.
Dubovsky (2018) reported a 1.1\% increase per year in the MCP from 1982-2017. However, this analysis included data from ground surveys conducted outside of the CPRV and NPRV aerial survey areas as part of the coordinated midcontinent survey, which we demonstrated were a valid index for the number of Sandhill Cranes outside of Nebraska at a point in time, but not an accurate estimate of abundance. These added cranes could have served as a constant and minimized the slope of the regression equation by having an over-weighted influence on earlier survey years with lower abundance values. Secondly, the Dubovsky (2018) growth rate valuation did not include abundance estimates from 2018 and 2019, which represented two of only five USFWS aerial survey estimates that fell within the $16 \%$ confidence intervals surrounding projections made with USFWS data. In a comprehensive assessment of the Eastern Population (EP) of Sandhill Cranes, Amundson and Johnson (2010) estimated the annual population increase using several different data sources. USFWS coordinated fall surveys of the EP demonstrated a 3.9\% growth rate from 1979 to 2009, Breeding Bird Survey (BBS) data indicated a growth rate of $10.0 \%$ per year from 1966 to 2007, and Christmas Bird Count (CBC) data from the wintering range outside of Florida showed a 10\% increase per year from 1990 to 2009.

Sandhill Crane population trends are the result of several demographic factors including survival rates, which tend to be relatively high for adults, and recruitment rates, which tend to be relatively low compared to most hunted North American avifauna (Drewien et al. 1995, Gerber et al. 2014). Little information exists concerning either recruitment or mortality rates regarding the $\mathrm{MCP}$, however, information from other populations suggests growth rates can range widely (Johnson and Kendall 1997, Amundson and Johnson 2010, Gerber et al. 2014). Drewien et al. (1995) estimated recruitment for a western concentration of MCP Lesser Sandhill Cranes at $11.2 \%$ annually (range $=9.9-12 \%$ ). Earlier data from Miller and Hatfield (1974) suggested a lower rate of recruitment for MCP via age ratio assessments at stopover sites in Saskatchewan, Canada (3.5 - 5.3\%). Bennett and Bennett (1990) found that Florida Sandhill Crane (G. c. pratensis) survival within the Okefenokee Swamp, Georgia, ranged from $82 \%$ to $94 \%$ annually $(\bar{x}=89 \%)$. Drewien et al. (1995) estimated survival rates for the Rocky Mountain Population Sandhill Crane population at between $91 \%$ and $95 \%$. It is possible that several of these survival and recruitment estimates are biased downward as demographic parameters derived from small subsets of entire populations tend 
to be underestimated as a result of animal movements such as dispersal (Sanz-Aguilar et al. 2016). Using a simplified approach, an annual adult survival rate of $94 \%$ and an annual recruitment rate of roughly $10 \%$ would result in a $4 \%$ annual growth rate, which is well within the range of demographic possibility (Gerber et al. 2014).

The three-year rolling average is probably the poorest metric to use to estimate MCP abundance because the majority of variation in the data has a downward bias. This model of the Sandhill Crane population displayed the lowest abundance of all models or raw data (Table 3). This model of abundance also did not perform well in terms of fit to survey year, suggesting unrealistic variation. Finally, data from the three-year rolling average fell within the Kinzel-based projection's cone of confidence $0 \%$ of the time, the USFWS-based projection's cone of confidence with $12 \%$ confidence intervals $5 \%$ of the time, and the cone of confidence with $16 \%$ confidence intervals just $15 \%$ of the time. All other observed three-year rolling average values were below the lower confidence interval for all projections. This suggests, by our metrics, that the three-year rolling average is a valid indicator of actual population abundance only $15 \%$ of the years surveyed between 2000 and 2019 or less. The five-year rolling maximum performed far better, being the top model predicted by survey year via AICc and falling within the $16 \%$ confidence level for the USFWS data-based projection $75 \%$ of the time. The US Fish and Wildlife Service should abandon the use of the three-year rolling average; it is not a biologically meaningful estimate, as most of the variation in the survey data is biased downward. Another way to correct this may be to conduct multiple surveys each year from mid-March to early-April to better account for variation in migration chronology (Ferguson et al. 1979, Caven et al. 2019).

Acknowledgments - This work was funded by the Platte River Whooping Crane Maintenance Trust, Inc. A.J. Caven was responsible for study concept, design, analysis, and writing the manuscript. D.M. Varner, J. Drahota, and A.J. Caven were responsible for manuscript review and provided data for the project. We want to thank B. Krohn for his feedback regarding this manuscript.

\section{Literature Cited}

Amundson CL and Johnson DH. (2010) Assessment of the Eastern Population Greater Sandhill Cranes (Grus canadensis tabida) Fall migration Survey, 1979-2009. U.S.
Fish and Wildlife Service, Migratory Bird Management, Region 3, St. Paul, Minnesota, USA.

Baasch DM, Farrell PD, Caven AJ, King KC, Farnsworth JM, and Smith CB. (2019) Sandhill Crane use of riverine roost sites along the central Platte River in Nebraska, USA. Monographs of the Western North American Naturalist 11(1): 1-13.

Barton K. (2016) MuMIn: Multi-Model Inference. R package version 1.15.6. https:/ /CRAN.R-project.org/ package=MuMIn

Benning DS and Johnson DH. (1987) Recent improvements to sandhill crane surveys in Nebraska's Central Platte Valley. Pages 10-16 in J.C. Lewis and J.W. Ziewitz, editors, Proceedings 1985 Crane Workshop. Platte River Whooping Crane Habitat Maintenance Trust and U.S. Fish and Wildlife Service, Grand Island, Nebraska, USA.

Bennett AJ and Bennett LA. (1990) Survival rates and mortality factors of Florida Sandhill cranes in Georgia. North American Bird Bander 15:85-88.

Buckley TJ. (2011) Habitat Use and Abundance Patterns of Sandhill Cranes in the Central Platte River Valley, Nebraska, 2003-2010. Thesis, University of Nebraska at Lincoln, Lincoln, Nebraska, USA. https:/ / digitalcommons. unl.edu/natresdiss/38/

Burnham KP, Anderson DR, and Huyvaert KP. (2011) AIC model selection and multimodel inference in behavioral ecology: some background, observations, and comparisons. Behavioral Ecology and Sociobiology 65:23-35.

Caven AJ, Brinley Buckley EM, King KC, Wiese JD, Baasch DM, Wright GD, Harner MJ, Pearse AT, Rabbe M, Varner DM, Krohn B, Arcilla N, Schroeder KD, Dinan KF. (In Press) Temporospatial shifts in Sandhill Crane staging in the Central Platte River Valley in response to climatic variation and habitat change. Monographs of the Western North American Naturalist 11, Article 4.

Currier PJ. (1982) The floodplain vegetation of the Platte River: phytosociology, forest development, and seedling establishment. Dissertation, Iowa State University, Ames, Iowa, USA. https:/ / lib.dr.iastate.edu/rtd/8339/

Davis CA. (2003) Habitat use and migration patterns of Sandhill Cranes along the Platte River, 1998-2001. Great Plains Research 13:199-216.

Dormann CF, Elith J, Bacher S, Buchmann C, Carl G, Carré G, Marquéz J.R.G, Gruber B, Lafourcade B., Leitão PJ, Münkemüller T, McClean C, Osborne PE, Reineking B, Schröder B, Skidmore AK, Zurell D, and Lautenbach S. (2013).Collinearity: a review of methods to deal with it and a simulation study evaluating their performance. Ecography 36:27-46.

Drewien RC, Brown WM, and Kendall WL. (1995) Recruitment in Rocky Mountain Greater Sandhill Cranes and comparison with other crane populations. Journal of Wildlife Management 59(2): 339-356. 
Dubovsky JA. (2018) Status and harvests of Sandhill Cranes: Mid-Continent, Rocky Mountain, Lower Colorado River Valley and Eastern Populations. Administrative Report, U.S. Fish and Wildlife Service, Lakewood, Colorado, USA.

Faanes CA, M.J. LeValley. (1993). Is the distribution of Sandhill Cranes of the Platte River changing? Great Plains Research 3:297-304.

Farmer AH, Cade BS, Terrell JW, and Henriksen JH. (2005) Evaluation of models and data for assessing Whooping Crane habitat in the Central Platte River, Nebraska. Scientific Investigations Report 2005-5123, U.S. Geological Survey, Reston, Virginia, USA.

Ferguson EL, Gilmer DS, Johnson DH, Lyman N, and Benning DS. (1979) Experimental surveys of Sandhill Cranes in Nebraska. Pages 41-52 in J.C. Lewis, editor, Proceedings 1978 Crane Workshop. Colorado State University Printing Service, Ft. Collins, Colorado, USA.

Gerber BD, Dwyer JF, Nesbitt SA, Drewien RC, Littlefield CD, Tacha TC, and Vohs PA. (2014) Sandhill Crane (Antigone canadensis), version 2.0. In A.F. Poole (Editor), The Birds of North America. (Ithaca, NY: Cornell Lab of Ornithology). https://doi.org/10.2173/bna.31

Gregory RD, Gibbons DW, and Donald PF. (2004) Bird census and survey techniques. In W.J. Sutherland, I. Newton, and R.E. Green (Editors), Bird ecology and conservation: A handbook of techniques, pp. 17-56. (Oxford, United Kingdom: Oxford University Press).

Harner MJ, Wright GD, and Geluso K. (2015) Overwintering Sandhill Cranes (Grus canadensis) in Nebraska, USA. Wilson Journal of Ornithology 127:457-466.

Horn JD, Joeckel RM, and Fielding CR. (2012) Progressive abandonment and planform changes of the central Platte River in Nebraska, central USA, over historical timeframes. Geomorphology 139:372-383.

Johnson DH and Kendall WL. (1997) Modeling the population dynamics of Gulf Coast Sandhill Cranes. In R.P. Urbanek and D.W. Stahlecker (Editors), Proceedings of the Seventh North American Crane Workshop, pp. 173-179. (Biloxi, Mississippi: North American Crane Working Group).

Kinzel PJ, Nelson JM, Parker RS, and Davis LR. (2006) Spring census of mid-continent Sandhill Cranes using aerial infrared videography. Journal of Wildlife Management 70(1):70-77.

Krapu GL, Reinecke KJ, and Frith CR. (1982) Sandhill Cranes and the Platte River. Transactions of the North American Wildife and Natural Resources Conference 47:543-552.

Krapu GL. (1999) Sandhill cranes and the Platte River. In K.P. Able (Editor), Gathering of angels: migrating birds and their ecology, pp. 103-117. (Ithaca, New York, USA: Cornell University Press).

Krapu GL, Brandt DA, Jones KL, and Johnson DH. (2011) Geographic distribution of the mid-continent population of Sandhill Cranes and related management applications. Wildlife Monographs 175:1-38

Krapu GL, Brandt DA, Kinzel PJ, and Pearse AT. (2014) Spring migration ecology of the mid-continent Sandhill Crane population with an emphasis on use of the Central Platte River Valley, Nebraska. Wildlife Monographs 189:1-41.

Lewis JC. (1974) Ecology of the Sandhill Crane in the southeastern Central Flyway. Doctoral Dissertation. Oklahoma State University, Stillwater, Oklahoma, USA. https://hdl.handle.net/11244/31718

Lewis JC. (1978) Spring census of Sandhill Cranes: factors affecting the Platte River crane census. Final report: Accelerated program for webless migratory game birds. Oklahoma Cooperative Wildlife Research Unit, Oklahoma State University, Stillwater, Oklahoma, USA.

Lewis JC. (1979) Factors affecting the spring inventory of Sandhill Cranes. In J.C. Lewis (Editor), Proceedings 1978 Crane Workshop, pp. 33 -39. (Ft. Collins, Colorado, USA: Colorado State University Printing Service).

Liddick T. (2019) Coordinated spring survey of mid-continent Sandhill Cranes. Branch of Migratory Bird Surveys, Migratory Bird Program, US Fish and Wildlife Service, Spearfish, South Dakota, USA.

Nelson ESD, Harris S, Soulsbury CD, Richards SA, and Stephens PA. (2010) Uncertainty in population growth rates: determining confidence intervals from point estimates of parameters. PLoS One 5(10):e13628.

Norling BS, Anderson SH, and Hubert WA. (1992) Temporal patterns of Sandhill Crane roost site use in the Platte River. Proceedings of the North American Crane Workshop 6: 106-113.

Nowald G, Fanke J, and Hansbauer MM. (2018) Linking Crane Life History and Feeding Ecology with Natural Habitats and Agricultural Lands. In J.E. Austin, K.L. Morrison, and J.T. Harris (Editors), Cranes and Agriculture: A Global Guide for Sharing the Landscape, pp. 18-34. (Baraboo, Wisconsin, USA: International Crane Foundation).

Pearse AT, Krapu GL, Brandt DA, and Kinzel PJ. (2010) Changes in agriculture and abundance of Snow Geese affect carrying capacity of Sandhill Cranes in Nebraska. Journal of Wildlife Management 74(3):479-488.

Pearse AT, Krapu GL, Brandt DA, and Sargeant GA. (2015) Timing of spring surveys for midcontinent sandhill cranes. Wildlife Society Bulletin 39(1):87-93.

Rousseeuw PJ and Van Zomeren BC. (1990) Unmasking multivariate outliers and leverage points. Journal of the American Statistical Association 85(411): 633-639.

Sanz-Aguilar A, Igual JM, Oro D, Genovart M, and Tavecchia G. (2016) Estimating recruitment and survival in partially monitored populations. Journal of Applied Ecology 53(1):73-82.

Schuwirth N, Borgwardt F, Domisch S, Friedrichs M, Kattwinkel M, Kneis D, Kuemmerlen M, Langhans SD, 
Martinez-Lopez J, and Vermeiren P. (2019) How to make ecological models useful for environmental management. Ecological Modelling 411: 108784.

Sidle JG, Miller ED and Currier PJ. (1989) Changing habitats in the Platte River Valley of Nebraska. Prairie Naturalist 21:91-104.

Sidle JG, Nagel HG, Clark R, Gilbert C, Stuart D, and Willburn K. (1993) Aerial Thermal Infrared Imaging of Sandhill Cranes of the Platte River, Nebraska. Remote Sensing of the Environment 43:333-341.

Silcock WR, and Jorgensen JG. (2019) Sandhill Crane (Antigone canadensis), Version 1.0. In Birds of Nebraska - Online. https:/ / birds.outdoornebraska.gov/ sandhill-crane/

Smith ND. (1971) Transverse bars and braiding in the lower Platte River, Nebraska. Geological Society of America Bulletin 82:3407-3420.

Sparling DW, Krapu GL. (1994) Communal roosting and foraging behavior of staging sandhill cranes. The Wilson Bulletin 106:62-77.

Stewart G. (2009) Meta-analysis in applied ecology. Biology letters 6(1): 78-81.

Tacha TC, Vohs PA, and Iverson GC. (1984) Migration routes of Sandhill Cranes from mid-continent North America. Journal of Wildlife Management 48:1028-33.
U.S. Fish and Wildlife Service (USFWS). (1981) The Platte River Ecology Study: Special Research Report. Northern Prairie Wildlife Research Center, Jamestown, North Dakota, USA.

Varner DM, Pearse AT, Bishop AA, Davis JI, Denton JC, Grosse RC, Johnson HM, Munter EJ, Schroeder KD, Spangler RE, Vrtiska MP, Wright AE. (2019) Roosting habitat use by Sandhill Cranes and waterfowl on the North and South Platte Rivers in Nebraska. Journal of Fish and Wildlife Management.

Walkinshaw LH. (1956) Two visits to the Platte Rivers and their Sandhill Crane migration. Nebraska Bird Review 24:18-21.

Warnock N. (2010) Stopping vs. staging: the difference between a hop and a jump. Journal of Avian Biology 41(6): 621-626.

Wheeler RH and Lewis JC. (1973) Trapping techniques for sandhill crane studies in the Platte River Valley. US Department of the Interior, Fish and Wildlife Service, Bureau of Sport Fisheries and Wildlife, Vol. 107.

White GC. (2005) Correcting wildlife counts using detection probabilities. Wildlife Research 32(3): 211-216.

Williams GP. (1978) The case of the shrinking channels: The North Platte and Platte Rivers in Nebraska. Geological Survey Circular 781, U.S. Geological Survey, Arlington, Virginia, USA. 